\title{
Poly(3-hydroxybutyrate-co-3-hydroxyvalerate) co-produced with L-isoleucine in Corynebacterium glutamicum WM001
}

\author{
Wenjian Ma ${ }^{1,3}$, Jianli Wang ${ }^{1,3}$, Ye Li ${ }^{1,2}$, Lianghong Yin ${ }^{2}$ and Xiaoyuan Wang 1,2,3*(])
}

\begin{abstract}
Background: Co-production of polyhydroxyalkanoate (PHA) and amino acids makes bacteria effective microbial cell factories by secreting amino acids outside while accumulating PHA granules inside. Poly(3-hydroxybutyrate-co3-hydroxyvalerate) (PHBV) is one of the PHAs with biocompatibility and fine mechanical properties, but its production is limited by the low level of intracellular propionyl-CoA.

Results: L-Isoleucine producing Corynebacterium glutamicum strain WM001 were analyzed by genome and transcriptome sequencing. The results showed that the most over-expressed genes in WM001 are relevant not only to L-isoleucine production but also to propionyl-CoA accumulation. Compared to the wild-type C. glutamicum ATCC13869, the transcriptional levels of the genes $\operatorname{prp} C 2$, prpD2, and prpB2, which are key genes relevant to propionyl-CoA accumulation, increased $2^{6.7}, 2^{5.8}$, and $2^{8.4}$-folds in WM001, respectively; and the intracellular level of propionyl-CoA increased 16.9-fold in WM001. When the gene cluster phaCAB for PHA biosynthesis was introduced into WM001, the recombinant strain WM001/pDXW-8-phaCAB produced $15.0 \mathrm{~g} / \mathrm{L}$ PHBV with high percentage of 3-hydroxyvalerate as well as $29.8 \mathrm{~g} / \mathrm{L} \mathrm{L}$-isoleucine after fed-batch fermentation. The maximum 3-hydroxyvalerate fraction in PHBV produced by WM001/pDXW-8-phaCAB using glucose as the sole carbon source could reach $72.5 \%$, which is the highest reported so far.

Conclusions: Genome and transcriptome analysis showed that C. glutamicum WM001 has potential to accumulate L-isoleucine and propionyl-CoA pool. This was experimentally confirmed by introducing the phaCAB gene cluster into WM001. The recombinant strain WM001/pDXW-8-phaCAB produced high levels of PHBV with high 3-hydroxyvalerate fraction as well as L-isoleucine. Because of its high level of intracellular propionyl-CoA pool, WM001 might be used for producing other propionyl-CoA derivatives.
\end{abstract}

Keywords: Corynebacterium glutamicum, L-Isoleucine, PHBV, 3HV fraction, Propionyl-CoA

\section{Background}

L-Isoleucine is used as a component of cosmetics, animal feed additives, and pharmaceuticals [1]. Industrial producers of L-isoleucine were mostly Corynebacterium glutamicum [2]. In C. glutamicum, L-isoleucine synthesis from L-aspartate involves ten reactions, five of them are feedback-inhibited by L-threonine or L-isoleucine

\footnotetext{
*Correspondence: xwang@jiangnan.edu.cn

1 State Key Laboratory of Food Science and Technology, Jiangnan

University, 1800 Lihu Avenue, Wuxi 214122, China

Full list of author information is available at the end of the article
}

[2]. Several L-isoleucine producers have been obtained by random mutation, site-directed mutagenesis, and rational metabolic engineering [1,3-10]. Polyhydroxyalkanoates (PHAs) are natural biodegradable and biocompatible polyesters with piezoelectricity and flexible mechanical properties and are potential alternatives for petroleum-based plastics [11]. PHAs accumulated in various microorganisms and plants for storing carbon and energy under nutrient imbalance [12] and could be naturally degraded within $100 \mathrm{~h}$ in the soil [11].

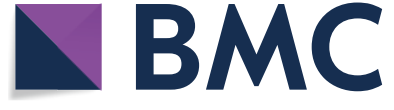

(c) The Author(s) 2018. This article is distributed under the terms of the Creative Commons Attribution 4.0 International License (http://creativecommons.org/licenses/by/4.0/), which permits unrestricted use, distribution, and reproduction in any medium, provided you give appropriate credit to the original author(s) and the source, provide a link to the Creative Commons license, and indicate if changes were made. The Creative Commons Public Domain Dedication waiver (http://creativecommons.org/ publicdomain/zero/1.0/) applies to the data made available in this article, unless otherwise stated. 
The major PHA is poly(3-hydroxybutyrate) (PHB) [13], however, the later discovered poly(3-hydroxybutyrateco-3-hydroxyvalerate) (PHBV) owns better biocompatibility and mechanical properties, which makes PHBV more proper for the pharmaceutical application [14]. 3 -Hydroxyvalerate (3HV) derived from propionyl-CoA is a crucial intermediate of PHBV; high fraction of $3 \mathrm{HV}$ in PHBV improves strength and flexibility of the polyester [15]. However, 3HV fractions are usually low in most PHBV products due to the propionyl-CoA limitation (Table 1). Improving the $3 \mathrm{HV}$ fraction in PHBV could be achieved by addition of the related precursors of propionyl-CoA, such as propionate [16], valerate [17], succinate [18], or L-threonine [19]; but such addition increases the cost and retards the cell growth (Table 1). Study of PHBV life cycle indicates that biopolymers like PHBV could be largely independent of fossil fuels in the future [20]. Current production scale of PHBV is about 2000 tons per year but its expectable production scale is around 50,000 tons per year.

Since Gram-negative bacteria synthesize large amount of immunogenic lipopolysaccharide which might contaminate the products and become a latent hazard in medical and food container application [21], PHBV are usually produced by using Gram-positive bacteria, such as Nocardia, Rhodococcus, Bacillus, Corynebacterium. Nocardia and Rhodococcus could naturally accumulate PHBV but are commercially non-viable [20], Bacillus could produce PHBV [19] but requires addition of extra threonine and cyanocobalamin, Corynebacterium could produce PHBV [22] but requires the addition of propionate in the medium. PHA could be co-produced with amino acids, such as L-glutamate [23], L-tryptophan [24], L-arginine [25], and succinate [26]. The co-productions positively affected the transcription of key enzymes, increased the product yield, rearranged the cofactor flux, and improved the cell growth.

In this study, the gene cluster phaCAB which contains the three key genes for PHA biosynthesis into a L-isoleucine producing $C$. glutamicum strain WM001, resulting in the strain WM001/pDXW-8-phaCAB. WM001/ pDXW-8-phaCAB produced high levels of PHBV with high $3 \mathrm{HV}$ fraction as well as L-isoleucine, using glucose as the sole carbon source.

\section{Methods}

\section{Strains, plasmids, and genetic methods}

Bacterial strains used in this study are listed in Table 2. L-isoleucine-producing C. glutamicum strain WM001 (CCTCC No. M2016303) was originally isolated from soil, and is closely related to C. glutamicum strain ATCC13869, based on their 16S rDNA sequences. Plasmid preparation kit, gel extraction kit, and DNA purification kit were purchased from Sangon Biotech (Shanghai, China). phaCAB cluster was amplified from $\mathrm{pBHR} 68$ using primers phaCAB-F (5'-CTG GAAT TCAGA AGG AGA ATC AAATCATGGCGA CCGG-3' (restriction site underlined)) and phaCAB$\mathrm{R}$ (5'-CCGCTCGAGAGGTCAGCCCATATGCAG G-3' (restriction site underlined)). The PCR product was digested with EcoRI and XhoI and ligated into pDXW-8 [27] which was similarly digested, resulting in pDXW-8-phaCAB. Similarly, the phaAB cluster was amplified using primer pairs phaAB-F (5'-CGGAA TTCAGAAGGAGATATACCATGACTGACGTTGTC ATCG-3' (restriction site underlined)) and phaAB$\mathrm{R}$ (5'-CCGCTCGAGAGGTCAGCCCATATGCAG G-3' (restriction site underlined)) and ligated into

Table 1 Comparison of the reported PHBV producers

\begin{tabular}{|c|c|c|c|c|}
\hline Strain & Carbon source & $3 \mathrm{HV}$ fraction $(\mathrm{mol} / \mathrm{mol})(\%)$ & DCW (g/L) & References \\
\hline Agrobacterium sp. & Propionate & 50 & 11 & [59] \\
\hline Salmonella typhimurium & Glycerol, propionate & 30.6 & - & [54] \\
\hline Alcaligenes sp. & Glucose, levulinic acid & 76.5 & 4.03 & {$[60]$} \\
\hline R. eutropha & Glucose, valerate & 62.7 & 110.2 & [17] \\
\hline R. aetherivorans & Acetate & 79 & 2.5 & {$[47]$} \\
\hline H. mediterranei & Starch & 13.4 & 7.01 & [61] \\
\hline C. glutamicum & Glucose, propionate & 28 & 12.0 & {$[22]$} \\
\hline E. coli & Glucose & 25.4 & - & [51] \\
\hline R. eutropha & Glucose & 26.0 & 132.8 & {$[62]$} \\
\hline Bacillus spp. & Glucose, L-threonine & 48 & 2.02 & [19] \\
\hline C. necator & $\begin{array}{l}\text { Glucose, levulinic acid, sodium } \\
\text { propionate }\end{array}$ & 80 & - & {$[56]$} \\
\hline E. coli & Glucose, propionate & 67.9 & 2.9 & {$[16]$} \\
\hline C. glutamicum & Glucose & 75.2 & 76 & This work \\
\hline
\end{tabular}


Table 2 Strains and plasmids used in the study

\begin{tabular}{lll}
\hline Strains or plasmids & Description & Sources \\
\hline Strains & & \\
DH5a & E. coli & NEB \\
DH5a/pDXW-8 & DH5a harboring pDXW-8 & This study \\
DH5a/pDXW-8-phaA & DH5a harboring pDXW-8-phaA & This study \\
DH5a/pDXW-8-phaAB & DH5a harboring pDXW-8-phaAB & This study \\
DH5a/pDXW-8-phaCAB & DH5a harboring pDXW-8-phaCAB & This study \\
ATCC13869 & Wild-type C. glutamicum & ATCC \\
ATCC13869/pDXW-8 & ATCC13869 harboring pDXW-8 & This study \\
ATCC13869/pDXW-8-phaCAB & ATCC13869 harboring pDXW-8-phaCAB & This study \\
WM001 & C. glutamicum L-isoleucine producer & CCTCC \\
WM001/pDXW-8 & WM001 harboring pDXW-8 & This study \\
WM001/pDXW-8-phaA & WM001 harboring pDXW-8-phaA & This study \\
WM001/pDXW-8-phaAB & WM001 harboring pDXW-8-phaAB & This study \\
WM001/pDXW-8-phaCAB & WM001 harboring pDXW-8-phaCAB & This study \\
Plasmids & & Template plasmid of phaCAB cluster \\
pBHR68 & Shuttle vector between E. coli and C. glutamicum \\
pDXW-8 & pDXW-8 harboring phaA & [27] \\
pDXW-8-phaA & pDXW-8 harboring phaAB & This study \\
pDXW-8-phaAB & pDXW-8 harboring phaCAB & This study \\
pDXW-8-phaCAB & & This study \\
\hline
\end{tabular}

pDXW-8, resulting in pDXW-8-phaAB, the gene phaA was amplified using primer pairs phaA-F (5'-CGGAA TTCAGAAGGAGATATACCATGACTGACGTTGTC ATCG-3' (restriction site underlined)) and phaA-R (5'-CTGCTCGAGACCCCT TCC TTATTTGCGC-3' (restriction site underlined)) and ligated into $\mathrm{pDXW}-8$, resulting in pDXW-8-phaA. Plasmids pDXW-8-phaA, pDXW-8-phaAB, and pDXW-8-phaCAB were then transformed to C. glutamicum ATCC13869 and C. glutamicum WM001. E. coli DH5 $\alpha$ strains were grown at $37{ }^{\circ} \mathrm{C}$ in Luria-Bertani medium (10 g/L tryptone, $5 \mathrm{~g} / \mathrm{L}$ yeast extract, and $10 \mathrm{~g} / \mathrm{L} \mathrm{NaCl}, \mathrm{pH} 7.2)$. C. glutamicum strains were grown at $30{ }^{\circ} \mathrm{C}$ in LBHIS medium $(10 \mathrm{~g} / \mathrm{L}$ $\mathrm{NaCl}, 10 \mathrm{~g} / \mathrm{L}$ peptone, $5 \mathrm{~g} / \mathrm{L}$ yeast extract, $18.5 \mathrm{~g} / \mathrm{L}$ brain heart infusion, and $91 \mathrm{~g} / \mathrm{L} \mathrm{D}$-sorbitol). When necessary, $30 \mu \mathrm{g} / \mathrm{mL}$ kanamycin was added to the medium to maintain the plasmids, and $0.5 \mathrm{mM}$ isopropyl $\beta$-Dthiogalactoside was added to the medium for induction.

\section{Batch fermentation}

Corynebacterium glutamicum cells were inoculated at $30{ }^{\circ} \mathrm{C}$ for $36 \mathrm{~h}$ on the agar plate containing $5 \mathrm{~g} / \mathrm{L}$ glucose, $10 \mathrm{~g} / \mathrm{L}$ tryptone, $5 \mathrm{~g} / \mathrm{L}$ beef extract, $5 \mathrm{~g} / \mathrm{L}$ yeast extract, and $5 \mathrm{~g} / \mathrm{L} \mathrm{NaCl}$. A single colony was inoculated in $25 \mathrm{~mL}$ seed medium in a $500-\mathrm{mL}$ flask for $18 \mathrm{~h}$ until $\mathrm{OD}_{562}$ reached 10 . The seed culture was then inoculated into $25 \mathrm{~mL}$ fermentation medium in 500 -mL flasks, the initial $\mathrm{OD}_{562}$ was adjusted to 1 . Seed medium contains
$30 \mathrm{~g} / \mathrm{L}$ glucose, $5 \mathrm{~g} / \mathrm{L}\left(\mathrm{NH}_{4}\right)_{2} \mathrm{SO}_{4}, 1 \mathrm{~g} / \mathrm{L} \mathrm{KH}_{2} \mathrm{PO}_{4}, 0.5 \mathrm{~g} / \mathrm{L}$ $\mathrm{MgSO}_{4}$, and $30 \mathrm{~g} / \mathrm{L}$ corn steep liquor, $\mathrm{pH} 7.2$ adjusted with $5 \mathrm{M} \mathrm{NaOH}$. Flask fermentation medium contains $130 \mathrm{~g} / \mathrm{L}$ glucose, $35 \mathrm{~g} / \mathrm{L}\left(\mathrm{NH}_{4}\right)_{2} \mathrm{SO}_{4}, 1 \mathrm{~g} / \mathrm{L} \mathrm{KH}_{2} \mathrm{PO}_{4}$, $0.5 \mathrm{~g} / \mathrm{L} \mathrm{MgSO}_{4}$ and $15 \mathrm{~g} / \mathrm{L}$ corn steep liquor, initial pH 7.2 adjusted with $5 \mathrm{M} \mathrm{NaOH}$ and maintained with $20 \mathrm{~g} / \mathrm{L} \mathrm{CaCO}_{3}$. Tryptone and yeast extract were purchased from Oxoid (Basingstoke, UK), and corn steep liquor from North China pharmaceutical corporation (Shijiazhuang, China). Other reagents were purchased from Sinopharm chemical reagent corporation. $30 \mu \mathrm{g} /$ $\mathrm{mL}$ kanamycin was added in both seed and fermentation medium before inoculation, and $0.5 \mathrm{mM}$ IPTG was added $6 \mathrm{~h}$ after inoculation. Flask cultivation was performed in a rotary shaker at $200 \mathrm{rpm}$ and $30{ }^{\circ} \mathrm{C}$ for $96 \mathrm{~h}$. Samples were collected every $12 \mathrm{~h}$ to determine the optical density and levels of glucose, organic acids, amino acids and PHA.

\section{Fed-batch fermentation}

Corynebacterium glutamicum cells were first cultivated in $60 \mathrm{~mL}$ seed medium in 500-mL flasks for $18 \mathrm{~h}$, then transferred into a 3-L fermentor (New Brunswick Scientific, New Brunswick, New Jersey) with 1.14 L fermentation medium. The fed-batch fermentation medium contains $130 \mathrm{~g} / \mathrm{L}$ glucose, $10 \mathrm{~g} / \mathrm{L}\left(\mathrm{NH}_{4}\right)_{2} \mathrm{SO}_{4}, 1 \mathrm{~g} / \mathrm{L}$ $\mathrm{KH}_{2} \mathrm{PO}_{4}, 0.5 \mathrm{~g} / \mathrm{L} \mathrm{MgSO}_{4}$ and $15 \mathrm{~g} / \mathrm{L}$ corn steep liquor; initial $\mathrm{pH}$ was adjusted to 7.2 with $5 \mathrm{M} \mathrm{NaOH}$ and 
maintained with 50\% ammonia. After 6 h, 0.5 mM IPTG was added for induction. Samples were collected every $12 \mathrm{~h}$ to determine the optical density and levels of glucose, organic acids, amino acids and PHA. The aeration rate was $1 \mathrm{~L} / \mathrm{min}$. The dissolved oxygen was cascaded to the speed of revolution ( 400 to $800 \mathrm{rpm}$ ) and controlled as $30 \%$ for cell growth before $24 \mathrm{~h}$, then $15 \%$ for PHA and L-isoleucine production. The residual glucose was maintained above 40 with $500 \mathrm{~g} / \mathrm{L}$ glucose solution. During the fermentation, too much foam could cause serious culture spill. This often happened during log phase because of the rapid cell growth. 3-4 drops of anti-foam solution were added several times to inhibit foam growing, but too much anti-foam (more than 15 drops) would be harmful to cell growth. If the foam keeps growing, the aeration rate can be decreased to $0.5 \mathrm{~L} / \mathrm{min}$ or under.

\section{Determination of amino acids, glucose, and organic acids} For amino acids determination, reverse phase high-pressure liquid chromatography (HPLC) was employed with an Agilent 1200 system (Agilent Technologies, Waldbronn, Germany) equipped with Thermo Hypersil ODS-2 column (5 $\mathrm{mm}$ particle, $250 \mathrm{~mm} \times 4.6 \mathrm{~mm}$ ) (Cheshire, UK) and diode array detection system. Buffer A contains $955 \mathrm{~mL} 0.1 \mathrm{M}$ sodium acetate, $5 \mathrm{~mL}$ tetrahydrofuran and $0.2 \mathrm{~mL}$ triethylamine per liter, $\mathrm{pH}$ 7.2. Buffer B contains $200 \mathrm{~mL} 0.1 \mathrm{M}$ sodium acetate $(\mathrm{pH} 7.2), 400 \mathrm{~mL}$ methanol and $400 \mathrm{~mL}$ acetonitrile per liter. Sample broths were centrifuged at $10,000 \mathrm{rpm}$ for $5 \mathrm{~min}$, the supernatants were diluted 20 times with trichloroacetic acid and went through $0.22 \mu \mathrm{m}$ membrane filters. The supernatants were subsequently derivatized with $o$-phthalaldehyde reagent solution (Agilent Technologies, Waldbronn, Germany) and then detected at $338 \mathrm{~nm}$ with a flow rate of $1 \mathrm{~mL} / \mathrm{min}$.

For glucose determination, SBA-40C immobilized enzyme biosensor (Shandong province academy of sciences, China) was employed. Supernatants were diluted 100 times with distilled water, and $25 \mu \mathrm{L}$ was injected.

For organic acids determination, Agilent 1260 HPLC was employed for intracellular and extracellular organic acids quantification equipped with Diamonsil C18 column (5 $\mathrm{m}, 250 \mathrm{~mm} \times 4.6 \mathrm{~mm}$ No. 99603) (DiKMA technology, Beijing, China). A linear gradient elution procedure was employed as methanol: $\mathrm{H}_{2} \mathrm{O}$ :phosphate (from 5:95:0.05 to 60:40:0.05) in $20 \mathrm{~min}$. Samples were detected with an ultraviolet detector at emission wavelengths $210 \mathrm{~nm}$ with a flow rate of $0.9 \mathrm{~mL} / \mathrm{min}$.

\section{Qualitative and quantitative analysis of PHBV}

For PHA granules observation, samples were treated according to transmission electron microscopy (TEM) specimen preparation protocol [28], and the specimen was imaged with a JEOL JEM 2100 (JEOL Ltd., Tokyo, Japan).

For identification and quantification of PHBV, GC-2010 plus system (Shimadzu, Japan) was employed with a DBWAX column $(30 \mathrm{~m} \times 0.32 \mathrm{~mm}$ ) (Agilent Technologies, Waldbronn, Germany) and a flame ionization detector, and the injection temperature was $250{ }^{\circ} \mathrm{C}$. Cells were harvested by centrifugation at 10,000 rpm for $5 \mathrm{~min}$, washed twice with $\mathrm{pH} 7.2$ phosphate-buffered saline then lyophilized for $48 \mathrm{~h}$. About $20 \mathrm{mg}$ lyophilized cells, $2 \mathrm{~mL}$ methanol (with $3 \% \mathrm{H}_{2} \mathrm{SO}_{4}$ ) and $2 \mathrm{~mL}$ chloroform were added to esterification tubes and treated in boiled water for $6 \mathrm{~h}$. $1 \mathrm{~mL}$ distilled water was added to esterification tubes at room temperature, and rotary vibrated for $5 \mathrm{~min}$, then $0.5 \mathrm{~mL}$ of organic phase was collected and filtrated with $0.22 \mu \mathrm{m}$ filters (Sartorious, Germany). Calibration curves were constructed with commercially available PHB and PHBV (Sigma-Aldrich, Saint Louis, Missouri).

\section{Transcriptome analysis}

Corynebacterium glutamicum ATCC13869 and WM001 were cultured in a 3-L bioreactor, and cells were harvested at late log phase by centrifugation at $10,000 \mathrm{rpm}$ for $5 \mathrm{~min}$, washed twice with $\mathrm{PBS} \mathrm{pH} 7.2$, then resuspended in RNA safer stabilizer reagent from Wegene (Shanghai, China). Illumina TruSeq Ribo-Zero ${ }^{\mathrm{TM}}$ Stranded Total RNA Sample Preparation kit was used for cDNA library preparation, and biotinylated oligos combined with Ribo-Zero ${ }^{\text {TM }}$ rRNA removal beads were used to remove ribosome RNA. The RNA was fragmented into small pieces using divalent cations. Taking these short fragments as templates, random hexamer primer were used to synthesize the first-strand cDNA. The second strand cDNA was synthesized with DNA Polymerase I and RNase H. Short fragments were purified with QiaQuick PCR extraction kit and resolved with elution buffer for end reparation and adding poly(A). After that, the short fragments were connected with sequencing adapters. For amplification with PCR, we selected suitable fragments as templates, with respect to the result of agarose gel electrophoresis. At last, the library was sequenced with Illumina $\mathrm{HiSeq}^{\mathrm{TM}}$ 2000. The complete genome of C. glutamicum ATCC 13032 was used as the reference genome for RNA-sequence reads sequence alignment. The expression level of each gene was calculated using the reads per kilobases per million reads, the analysis results with a $p$ value $<0.05$ were corrected by the false discovery rate, which was set to $<0.001$. RNA-seq transcriptome analysis was conducted by BGI genomics (Shenzhen, China). 


\section{Determination of acetyl-CoA and propionyl-CoA}

The sample preparation procedures and LC/MS methods were described in the previous studies [29-31] with modifications. C. glutamicum cells were cultured in a $500-\mathrm{mL}$ flask for $24 \mathrm{~h}$ then transferred to pre-chilled Eppendorf tubes and centrifuged at $10,000 \mathrm{rpm}$ and $0{ }^{\circ} \mathrm{C}$ for $30 \mathrm{~s}$, the sediments were quickly washed twice with cold $0.9 \% \mathrm{NaCl}$ solution, and resuspended in $1 \mathrm{~mL}$ mixture of methanol, acetonitrile and $\mathrm{ddH}_{2} \mathrm{O}$ (45:45:10, $\mathrm{v} / \mathrm{v} / \mathrm{v}$ ) at $-20{ }^{\circ} \mathrm{C}$ with $0.1 \mathrm{M}$ formic acid for quenching, and then ultrasonicated at $0{ }^{\circ} \mathrm{C}$ for 5 min $(60$ cycles of $2 \mathrm{~s}$ running and $3 \mathrm{~s}$ interval). The supernatants were filtrated with $0.22 \mu \mathrm{m}$ filter and directly injected into a TSQ Quantum Ultra (Thermo Scientific, San Jose, CA, USA) with commercially available acetyl-CoA and propionylCoA (Sigma-Aldrich, Saint Louis, Missouri) as standards. Buffer A was $5 \mathrm{mM}$ ammonium acetate (Sigma-Aldrich, Saint Louis, Missouri). Buffer B was methanol (SigmaAldrich, Saint Louis, Missouri). Samples were eluted at a flow rate of $0.4 \mathrm{~mL} / \mathrm{min}$, acetyl-CoA (parent ion $\mathrm{m} / \mathrm{z}=810$, product ion $\mathrm{m} / \mathrm{z}=303$ ) and propionyl-CoA (parent ion $\mathrm{m} / \mathrm{z}=824$, product ion $\mathrm{m} / \mathrm{z}=317$ ) were detected and quantified in multi-reaction monitoring (MRM) mode according to the calibration curve. The data were analyzed and exhibited with Xcalibur.

\section{Results and discussion}

\section{Genome sequencing and transcriptome analysis of $C$.} glutamicum WM001

Corynebacterium glutamicum has been remarkable platform bacteria for producing L-isoleucine [32]. L-Isoleucine-producing C. glutamicum strain WM001 was originally isolated from soil, and is closely related to C. glutamicum strain ATCC13869, based on their $16 \mathrm{~S}$ rDNA sequences. In this study, the genome of WM001 was sequenced with single-molecule realtime sequencing and deposited to the NCBI (NZ CP022394.1, https://www.ncbi.nlm.nih.gov/nuccore/ CP022394). Profiles of the strain are available in NCBI with Biosample No. SAMN07337837 and Bioproject Accession No. PRJNA393604. Sequencing data were assembled and analyzed with Prodigal [33], HGAP [34], tRNAscan-SE [35], and Infernal 1.1 [36]. As a result, a single circular chromosome of 3,319,925 bp was generated with $54.0 \%$ GC content and no plasmids. The GC content of C. glutamicum WM001 is similar to the GC content of C. glutamicum ATCC13032 (53.8\%), ATCC14067(54.1\%), and ATCC13869 (54.2\%) [37]. There were 3070 protein-coding genes, 18 tRNAs, 60 rRNAs and 18 other non-coding RNAs in the genome of WM001.

Proteome analysis between WM001 and ATCC13869 has been studied but the mechanism of WM001 producing excessive L-isoleucine remains unclear [38]. To find out the global metabolic differences between WM001 and ATCC13869, transcriptome analysis was performed. Samples of WM001 and ATCC13869 were harvested at $24 \mathrm{~h}$ (late exponential stage) when the dry cell weights reached 33 and $36 \mathrm{~g} / \mathrm{L}$, respectively. Regulation threshold was set as twofold, as a result, 406 genes were up-regulated and 237 genes were down-regulated in WM001.

Transcriptome analysis results were shown in Fig. 1. As expected, $i l v N$, $i l v B$, thrB, hom, which related to L-isoleucine synthesis [10] were up-regulated by $2^{2.8}, 2^{2.4}$, $2^{2.7}$, and $2^{2.3}$-folds, respectively. L-Isoleucine exporter encoded by $\operatorname{brnFE}[8,39]$ were significantly up-regulated $2^{4.5}$-fold $(b r n F)$ and $2^{4.0}$-fold $(b r n E)$, which enhanced the secretion of L-isoleucine. This explains the high production of L-isoleucine in C. glutamicum strain WM001, and also suggests that BrnFE play an important role on L-isoleucine production in C. glutamicum [40]. In addition, the down-regulated of metE, leuC, leuD, ilvE, serC, $g \ln A, g l t B, g l t D$ reduced the metabolic flux towards other by-products $[41,42]$, thereby revealing the mechanism that extracellular levels of related amino acids in WM001 were much lower than that in wild-type [38]. Thus, the blocked and reserved carbon flux could be channeled towards L-isoleucine. On the other hand, most TCA cycle genes like acn, icd, sdhA,sdhB, sdhC, sdhD, fumC, mqo, $m d h$ were down-regulated $2^{2.1}, 2^{1.1}, 2^{2.5}, 2^{2.6}, 2^{2.4}, 2^{2.4}, 2^{1.4}$, $2^{1.4}$, and $2^{1.1}$-folds, respectively whereas $s u c C$ and $s u c D$ were up-regulated $2^{3.3}$ and $2^{2.5}$-folds due to catabolism of L-isoleucine and other amino acids. As the downregulated TCA cycle genes contributed to the L-lysine production in C. glutamicum [43], they might also affect L-isoleucine production. In addition, the changes on the regulation of oxidative phosphorylation, glycolysis pathway, pyruvate metabolism, amino acids biosynthesis from transcriptome profiling provide the integrated information of WM001 metabolism (Additional file 1: Table S2).

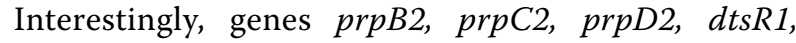
and $m s m A$ encoding the enzymes for propionyl-CoA catabolism were up-regulated $2^{8.4}, 2^{6.7}, 2^{5.8}, 2^{2.2}$, and $2^{2.3}$-folds, respectively (Fig. 1). This significantly activated propionyl-CoA catabolism suggests there might be excessive propionyl-CoA, i.e. a huge propionyl-CoA pool, in C. glutamicum WM001 cells.

\section{Overexpressing the phaCAB cluster not only produced PHA but also improved $\mathrm{L}$-isoleucine production}

In previous studies, PHB accumulation increased 23\% L-glutamate [23], 21\% succinate [26], 12\% L-tryptophan [24], and 21\% L-arginine yield [25], respectively. To test whether PHA accumulation could enhance L-isoleucine production as in these reports, and whether WM001 


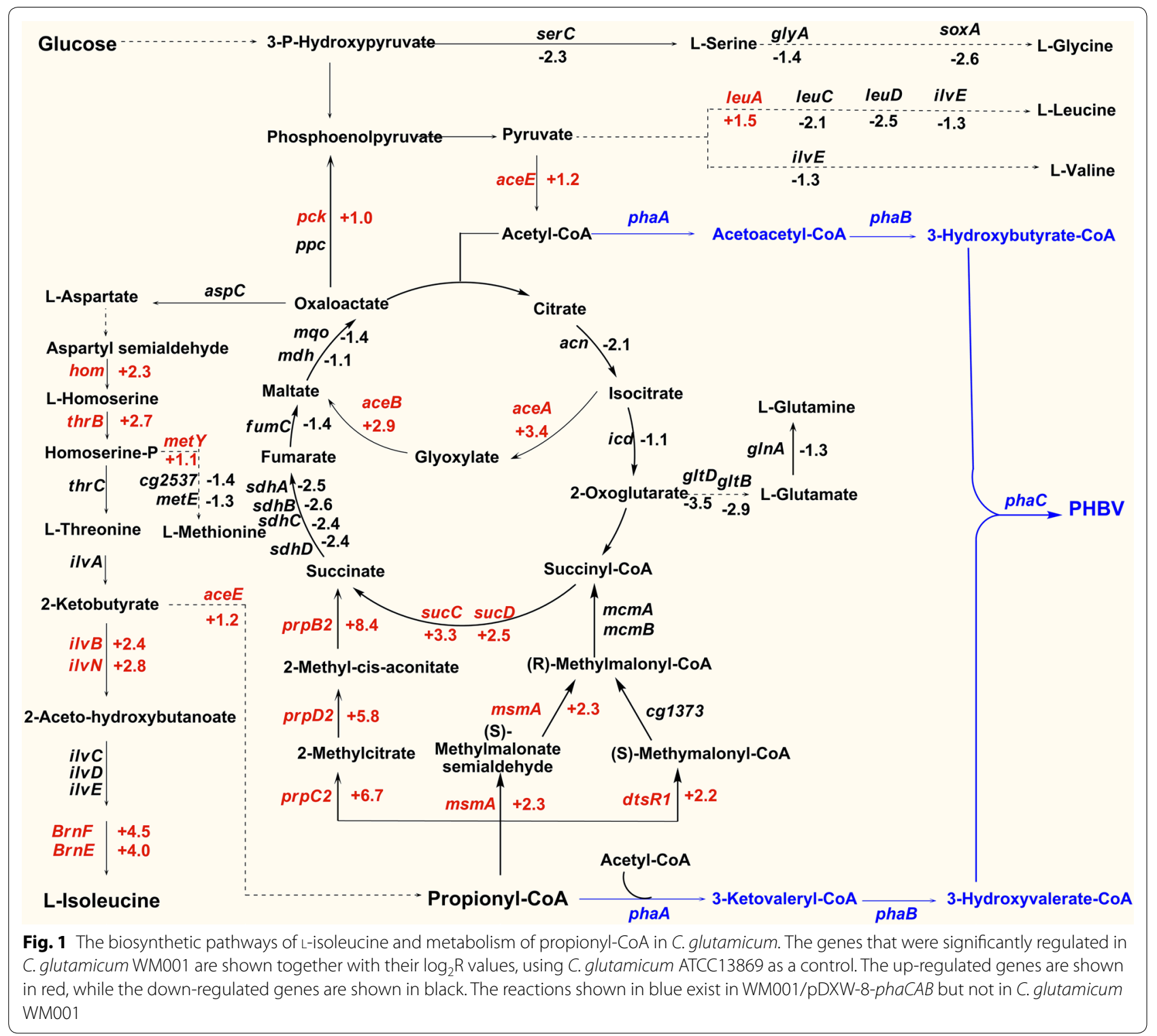

could use the propionyl-CoA pool to produce PHBV rather than $\mathrm{PHB}$, the phaCAB cluster was expressed in WM001. After $96 \mathrm{~h}, \mathrm{~L}$-isoleucine production and glucose consumption of the recombinants were analyzed (Fig. 3). WM001/pDXW-8-phaCAB produced $9.58 \mathrm{~g} / \mathrm{L}$ L-isoleucine while the control only reached $6.65 \mathrm{~g} / \mathrm{L}$ (Fig. 3a) at 96 h. Glucose consumption in WM001/ pDXW-8 and WM001/pDXW-8-phaCAB followed the same pattern (Fig. 3b) but less glucose was consumed in WM001/pDXW-8-phaCAB. The L-isoleucine yield on glucose in WM001/pDXW-8-phaCAB increased 65\% compared to the control. Since up-regulation of L-tryptophan and $\mathrm{L}$-arginine synthesis genes were observed when phaCAB expressed in E. coli and C. crenatum [24, 25], transcriptional levels of L-isoleucine biosynthesis genes were determined by RT-PCR. The results showed that lys $C$, hom, ilvA, and $i l v B N$ genes were up-regulated $2^{1.7}$, $2^{1.4}, 2^{1.5}$, and $2^{1.1}$-folds in WM001/pDXW-8-phaCAB, respectively. Our results were consistent with the above-mentioned studies, suggesting phaCAB expression could lead to up-regulation of L-isoleucine biosynthesis genes in C. glutamicum.

PHA production in WM001/pDXW-8-phaCAB was confirmed by TEM analysis (Fig. 2) and SEM analysis (Additional file 1: Figure S1). PHA granules were observed in WM001/pDXW-8-phaCAB but not in WM001/pDXW-8. These PHA granules occupied about $70 \%$ of the cell volume, and the cells containing PHA are 

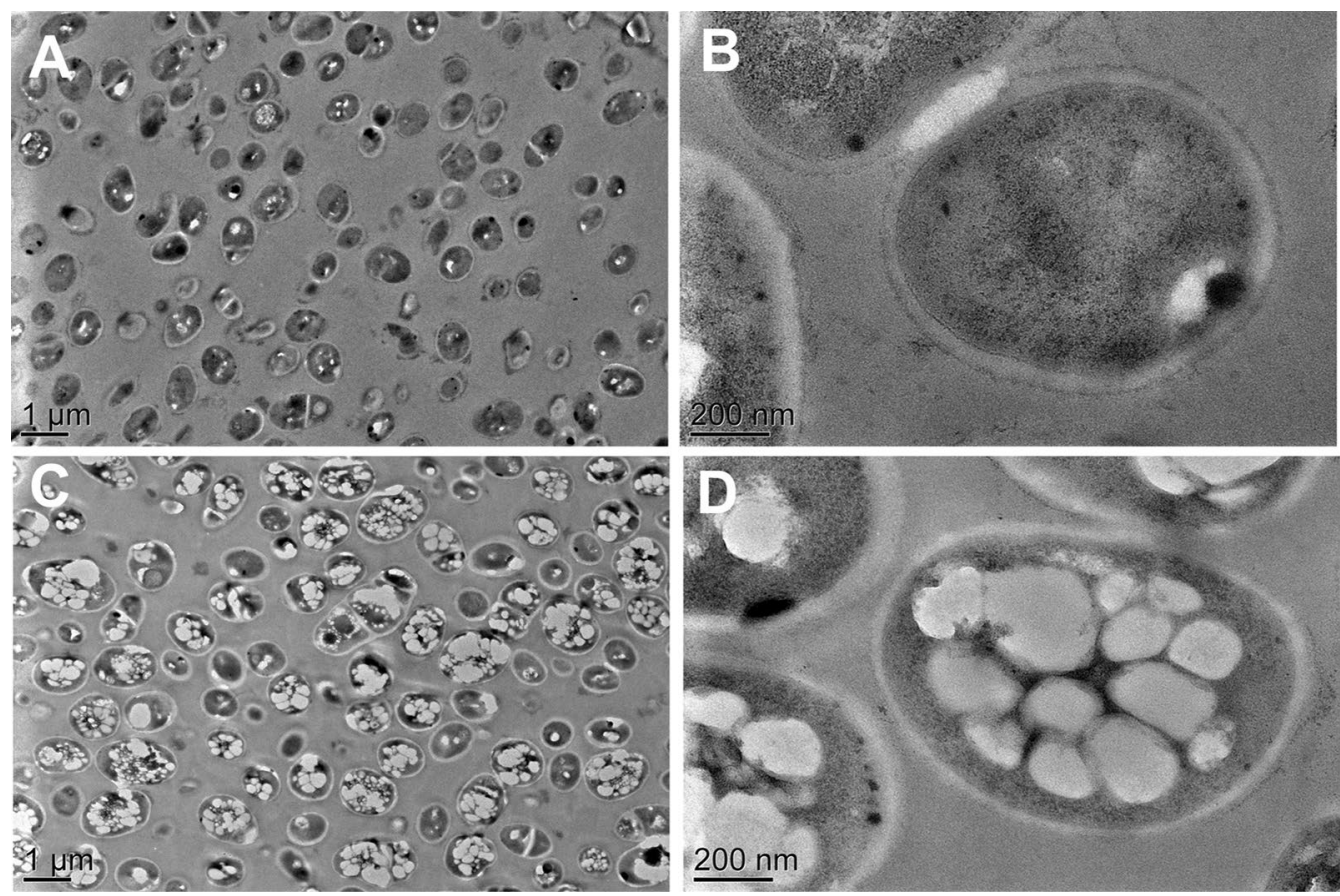

Fig. 2 TEM analysis of C. glutamicum WM001/pDXW-8 and WM001/pDXW-8-phaCAB cells. Intracellular PHA granules were observed in WM001/ pDXW-8-phaCAB but not in WM001/pDXW-8. A WM001/pDXW-8; B WM001/pDXW-8; CWM001/pDXW-8-phaCAB; D WM001/pDXW-8-phaCAB

larger than those containing no PHA (Fig. 2 and Additional file 1: Figure S1). During fermentation, WM001/ pDXW-8-phaCAB cells grew better than the control (Fig. 3c). PHA accumulation was found to facilitate the growth of E. coli [26], Pseudomonas oleovorans [44], and Aeromonas hydrophila [45], possibly because PHA synthesis improves resistance against stress through globe regulators, such as RpoS [44]. Although high levels of L-isoleucine production significantly inhibited the cell growth in our previous study [46], PHA synthesis can recover the cell growth and enhance L-isoleucine production simultaneously in C. glutamicum.

The gene cluster $p h a C A B$ consists of three genes phaC, phaA, and phaB. In this study, to investigate which gene or combinations lead to the enhancement of $\mathrm{L}$-isoleucine, WM001/pDXW-8-phaA and WM001/pDXW-8-phaAB which strengthened the supply of acetoacetyl-CoA and 3-hydroxybutyrate-CoA were similarly constructed respectively. After checking phaA and phaAB were well expressed via SDS-PAGE (Additional file 1: Figure S2). We tested both recombinants with batch fermentation as we previously tested WM001/pDXW-8-phaCAB. After $72 \mathrm{~h}$ fermentation, WM001/pDXW-8-phaA and WM001/pDXW-8-phaAB showed no significant enhancement of $\mathrm{L}$-isoleucine (Additional file 1: Table S1), that indicates it was the synthesis of PHA polymers rather than any intermediates that improved L-isoleucine production in WM001.

\section{WM001/pDXW-8-phaCAB produces PHBV with a high 3HV fraction}

The 3HV fractions in bio-based PHBV polymers were quite low without adding related precursors. Therefore several studies were conducted to improve $3 \mathrm{HV}$ fraction (Table 1). Since propionyl-CoA is the most crucial substrate of $3 \mathrm{HV}$, the propionyl-CoA pool size is very important. Unfortunately, endogenous propionyl-CoA is usually limited for its rapid conversion to succinate and succinyl-CoA (Fig. 1). Adding propionyl-CoA precursors like propionate, levulinic acid, threonine, succinate, valerate is the direct way to enhance $3 \mathrm{HV}$ fraction but the additions not only raise the cost but also inhibit the cell growth because of the toxicity of the precursors [22]. Without adding propionyl-CoA precursors, some microorganisms could produce PHBV from glucose, toluene, starch, acetate, but these microorganisms require extra supplements such as mevinolin and sodium chloride, which also brings extra costs and difficulties [47-50]. Some engineered microorganisms could use endogenous propionyl-CoA through the combination of citramalate pathway and threonine biosynthesis pathway but the $3 \mathrm{HV}$ fraction only reached $25.4 \%$ or less [51]. In 


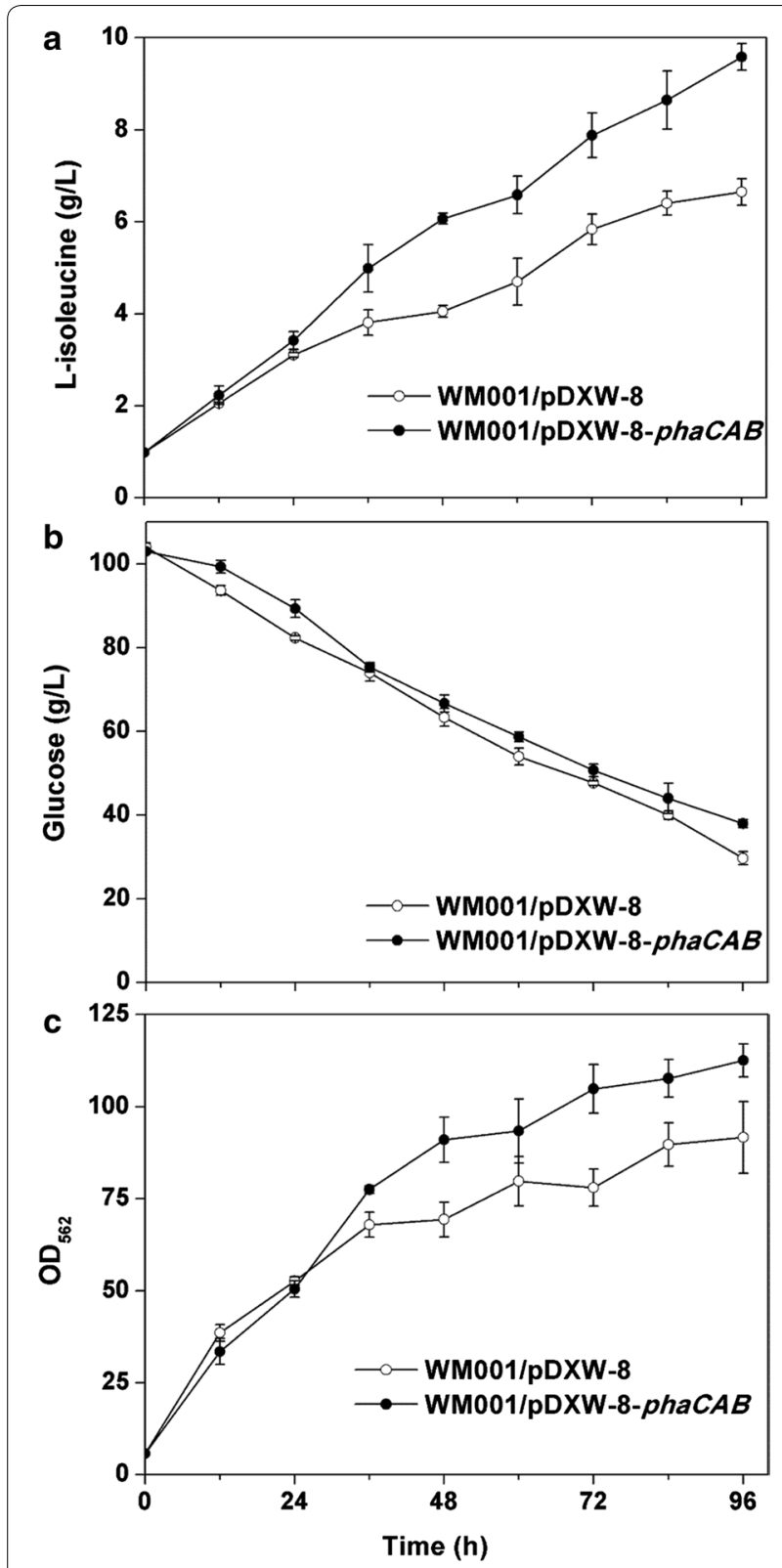

Fig. 3 Batch fermentation profiles of WM001/pDXW-8 and WM001/ pDXW-8-phaCAB cells. a The titer of L-isoleucine; b glucose; ${\text { c } D_{562}}_{2}$

Gram-positive bacteria, PHBV production without adding related precursor is not reported yet.

Since a huge propionyl-CoA pool was discovered in WM001, the PHA produced by WM001 recombinant could be PHBV. The intracellular PHA of WM001/ pDXW-8, WM001/pDXW-8-phaCAB, ATCC13869/ pDXW-8, and ATCC13869/pDXW-8-phaCAB were extracted and analyzed by gas chromatography (Fig. 4a). Standard PHBV with the $8 \%(\mathrm{~mol} / \mathrm{mol}) 3 \mathrm{HV}$ fraction yielded two peaks at 8.06 and $9.07 \mathrm{~min}$, and the former is much larger, suggesting that the 8.06 min peak is derived from $3 \mathrm{HB}$ while the other from $3 \mathrm{HV}$. Both 8.05 and 9.06 min peaks were observed in the spectrum of PHA from WM001/pDXW-8-phaCAB, and the area of the 9.06 min peak is larger than 8.05 min peak indicating that PHBV synthesized by WM001/pDXW-8-phaCAB contains a high level of $3 \mathrm{HV}$. In contrast, PHA samples from ATCC13869/pDXW-8-phaCAB showed a single 8.06 min peak and no 9.06 min peak (Fig. 4a), which was consistent with the previous study [52] and confirmed that ATCC13869/pDXW-8-phaCAB could not produce PHBV under the cultivation condition in this study. Two control samples showed no peaks, suggesting that $\mathrm{PHB}$ and PHBV were originated from phaCAB overexpression. The quantitative results showed that WM001 recombinant produced PHBV $[28.7 \%(\mathrm{w} / \mathrm{w}), 58.1 \%(\mathrm{~mol} / \mathrm{mol})$ 3HV, 9.4 g/L] while the wild-type ATCC13869 recombinant produced PHB [20.0\% (w/w), 6.7 g/L] (Fig. 4b). On the other hand, the $3 \mathrm{HV}$ and $3 \mathrm{HB}$ esters were confirmed by GC/MS (Additional file 1: Figure S3).

To confirm the intracellular propionyl-CoA pool in WM001, intracellular CoA esters of WM001 and ATCC13869 cells were extracted and quantified with LC-MS. In WM001, propionyl-CoA increased 16.9fold (from 0.08 to $1.35 \mu \mathrm{M}$ ) and acetyl-CoA increased 1.3-fold (from 3.80 to $5.00 \mu \mathrm{M}$ ). Meanwhile, the ratio of propionyl-CoA to acetyl-CoA increased 12-fold from 0.02 to 0.25 (Fig. 4c). The transcriptome analysis and the LC-MS quantification results of propionyl-CoA confirmed the existence of a huge propionyl-CoA pool in WM001. Where does the excessive propionyl-CoA come from? According to previous publications, there are at least six sources for propionyl-CoA production. (I) The $\beta$-oxidation, using fatty acid as substrate, this pathway does not exist in C. glutamicum [22]; (II) the propionate degradation, the most common source of propionyl-CoA. C. glutamicum could not produce PHBV without propionate in ATCC13869 [22]. Our results of ATCC13869 producing PHB were consistent with this study (Fig. 4a). On the other aspect, extracellular propionate of WM001/ pDXW-8-phaCAB and the control was determined before inoculation $(4.23$ and $4.23 \mathrm{~g} / \mathrm{L})$ and after fermentation $(2.39$ and $2.46 \mathrm{~g} / \mathrm{L})$. The propionate was probably brought in by corn steep liquor which is essential for biotin auxotroph C. glutamicum. More importantly, the $3 \mathrm{HV}$ in PHBV copolymer was way more than propionate consumed in the medium, needless to say, ATCC13869 recombinant produced $\mathrm{PHB}$, not $\mathrm{PHBV}$ with the same medium; (III) the 2-ketobutyrate pathway, propionylCoA could be synthesized from 2-ketobutyrate by pyruvate dehydrogenase complex. But the conversion rate of 2-ketobutyrate to propionyl-CoA is ten times slower than that of pyruvate to acetyl-CoA [53]. As 2-ketobutyrate is 


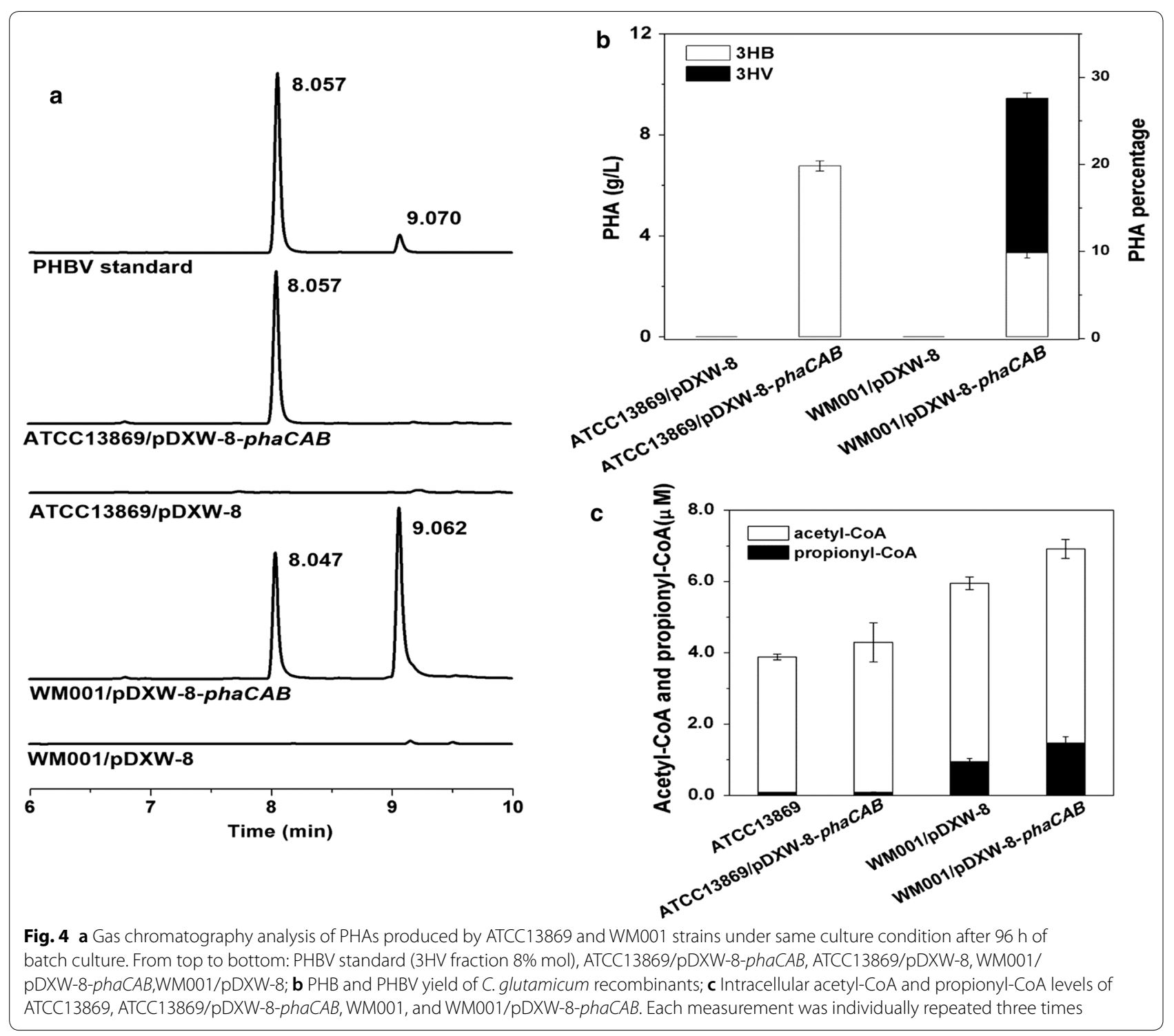

one of the crucial intermediates in L-isoleucine synthesis, there might be excessive 2-ketobutyrate in WM001, and could be channeled towards propionyl-CoA synthesis; (IV) the (2R)-methylmalonyl-CoA pathway, in which succinyl-CoA could convert to propionyl-CoA through $s b m$ and $y g f G$ genes [54], but this coenzyme vitamin $\mathrm{B}_{12}$ dependent pathway does not exist in C. glutamicum; (V) the levulinyl-CoA pathway, which was identified in $C$. necator. The acetyl-CoA and propionyl-CoA could be converted from levulinate [55] and used for PHBV production in C. necator [56]. (VI) other pathways, in Rhodococcus aetherivorans, PHBV could be produced with toluene or acetate but the mechanism remains obscure [47]. Among these above mentioned six possible sources, we intend to believe the excessive propionyl-CoA in WM001 might comes from 2-ketobutyrate (Source III).

In previous studies, $\mathrm{PHB}$ accumulation enhanced the synthesis of the co-products, as PHB consumed acetylCoA as the substrate, it could also enhance metabolites related to acetyl-CoA such as L-glutamate [23] and L-arginine [25]. In this study, we observed 8.9 and $10.6 \%$ increase of acetyl-CoA in WM001/pDXW-8-phaCAB and ATCC13869/pDXW-8-phaCAB than the control strains (Fig. 4c). The acetyl-CoA enhancement complemented with previous studies [23-25], suggesting that PHA production not only consumed acetyl-CoA substrate but also replenish the acetyl-CoA pool, that could explain the enhancement of these metabolites while PHA co-producing in the cells. On the other hand, the 
excessive acetyl-CoA was channeled towards the downregulated TCA cycle of WM001 (Fig. 1), that might be the reason that WM001/pDXW-8-phaCAB exhibit better growth than the control (Figs. $3 \mathrm{c}$ and $5 \mathrm{a}$ ).

\section{Co-production of L-isoleucine and PHBV in fed-batch fermentation}

Fed-batch fermentation of WM001/pDXW-8-phaCAB was performed, using WM001/pDXW-8 as the control. During the fermentation, the $\mathrm{pH}$ was kept between 7.2 and 7.4 because the fermentation would stop before stationary phase if the $\mathrm{pH}$ were lower than 7.0 according to our experiences. Glucose consumption of the two recombinants was similar (Fig. 5a). After 24 h, L-isoleucine concentration rapidly increased, and PHBV started to accumulate (Fig. 5c). At $24 \mathrm{~h}$, the $3 \mathrm{HV}$ mole fraction was only $31 \%$, as L-isoleucine rapidly accumulated during 24 and $72 \mathrm{~h}$ (Fig. 5b), the $3 \mathrm{HV}$ fraction sharply raised to $59 \%$ $(48 \mathrm{~h}$ ) and $72.5 \%$ (72 h) (Fig. 5c). The 3HV fraction at $72 \mathrm{~h}$

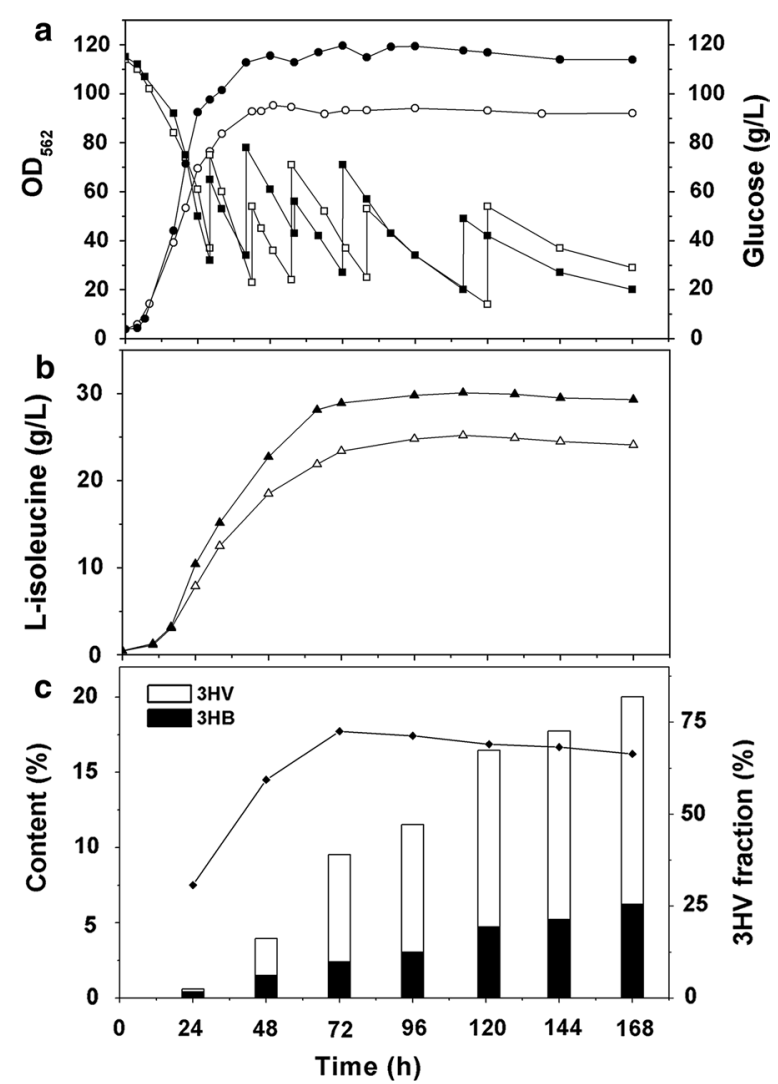

Fig. 5 Fed-batch fermentation profiles of C. glutamicum WM001/ pDXW-8 and WM001/pDXW-8-phaCAB. a OD 562 of WM001/ pDXW-8-phaCAB (solid circle) and WM001/pDXW-8 (open circle), residual glucose of WM001/pDXW-8-phaCAB (solid square) and WM001/pDXW-8 (open square); b L-isoleucine concentration produced by WM001/pDXW-8-phaCAB and WM001/pDXW-8; c PHBV content and $3 \mathrm{HV}$ fractions (solid diamond) of PHBV is $280 \%$ higher than the previous highest $3 \mathrm{HV}$ fraction with glucose as the only carbon source (Table 1). During 72 and $168 \mathrm{~h}$, the $3 \mathrm{HV}$ fraction decreased and reached $66.3 \%$ at the end of the fermentation (Fig. 5c). At $168 \mathrm{~h}$, WM001/pDXW-8-phaCAB produced 20.0\% PHBV with $66.2 \%(\mathrm{~mol} / \mathrm{mol}) 3 \mathrm{HV}$. As a result, WM001 recombinant produced PHBV with the $3 \mathrm{HV}$ fraction ranges from 31 to $72.5 \%$. $3 \mathrm{HV}$ fraction increased sharply as the L-isoleucine rapidly accumulated, suggesting that the $3 \mathrm{HV}$ metabolism was coupled with $\mathrm{L}$-isoleucine metabolism, which complemented our assumption that the excessive propionyl-CoA comes from 2-ketobutyrate.

As for L-isoleucine production, WM001/pDXW8-phaCAB produced $29.8 \mathrm{~g} / \mathrm{L}$ L-isoleucine, while the control produced $24.3 \mathrm{~g} / \mathrm{L}$ at $96 \mathrm{~h}$ (Fig. $5 \mathrm{~b}$ ). This titer is quite close to the highest reported titer i.e. $32.3 \mathrm{~g} / \mathrm{L}$ [57]. The yield on glucose increased $27 \%$ to $0.129 \mathrm{~g} / \mathrm{g}$ glucose which is also close to the highest, i.e. $0.137 \mathrm{~g} / \mathrm{g}$ [58], thus indicating that WM001/pDXW-8-phaCAB consumed glucose economically to produce both L-isoleucine and PHBV. Moreover, PHA accumulation depended on high $\mathrm{C}: \mathrm{N}$ ratio, the $\mathrm{L}$-isoleucine yield reached the maximum at $96 \mathrm{~h}$, but PHBV yield reached the maximum until $168 \mathrm{~h}$ mostly because of the adequate nitrogen source at the beginning, when nitrogen source was depleted by L-isoleucine production, $\mathrm{C}: \mathrm{N}$ ratio increased, and the supplied carbon source was used for PHBV production.

Our results showed that PHBV accumulation increased 44 and $23 \% \mathrm{~L}$-isoleucine production in batch and fed-batch fermentation. The yield on glucose also increased 65 and $27 \%$. With the high yield of both L-isoleucine and PHBV with the low-cost medium, C. glutamicum WM001 recombinant has a great industrial potential for PHBV and L-isoleucine co-production. With glucose as the only carbon source, WM001/pDXW-8-phaCAB could produced PHBV with a high $3 \mathrm{HV}$ fraction, which helps saving the cost of the addition of related precursors of PHBV (Table 1). Furthermore, the excessive propionyl-CoA could be channeled into other propionyl-CoA derivatives such as 1-propanol, 1-butanol, and higher alcohols. With the genome and transcriptome analyzed, C. glutamicum WM001 could act as a Gram-positive platform microorganism. As for the further enhancement of PHBV productivity, the fermentation parameters need to be optimized aiming at high-density culture, along with integrated omics analysis and finetuned metabolic flux, WM001 would become a promising PHBV and $\mathrm{L}$-isoleucine microbial producer.

\section{Conclusions}

According to the omics analysis, we preliminary revealed the mechanisms of $\mathrm{L}$-isoleucine over-production in WM001. More importantly, the unexpected activated propionyl-CoA catabolism was detected and 
an assumed huge propionyl-CoA pool was discovered and confirmed. In WM001, propionyl-CoA increased 16.9-fold and the ratio of propionyl-CoA to acetylCoA increased 12.5-fold compared to the wild-type. After phaCAB cluster was introduced, the recombinant strain produced $15.0 \mathrm{~g} / \mathrm{L}$ PHBV with $66.3 \% 3 \mathrm{HV}$ in fed-batch fermentation during which the maximum $3 \mathrm{HV}$ fraction reached $72.5 \%$, which is $280 \%$ higher than the previous highest $3 \mathrm{HV}$ fraction with glucose. Thus, WM001 was characterized as an efficient L-isoleucine and PHBV co-producer and potential producers for propionyl-CoA derivatives.

\section{Additional file}

Additional file 1: Figure S1. SEM analysis of WM001/pDXW-8 and WM001/pDXW-8-phaCAB. Figure S2. SDS-PAGE of WM001 recombinants: Lane 1,WM001/pDXW-8-phaCAB; Lane 2, WM001/pDXW-8-phaAB; Lane 3, WM001/pDXW-8-phaA; Lane 4, WM001/pDXW-8; Lane 5, marker. Figure S3. GC/MS analysis of PHA produced by WM001/pDXW-8phaCAB. Table S1. Batch fermentation of WM001 recombinants after 72 h. Table S2. Differentially expressed genes between WM001 and ATCC13869.

\section{Abbreviations}

PHA(s): polyhydroxyalkanoate(s); PHB: poly(3-hydroxybutyrate); PHBV: poly(3hydroxybutyrate-co-3-hydroxyvalerate); DCW: dry cell weight; TEM: transmission electron microscopy; SEM: scanning electron microscopy.

\section{Authors' contributions}

WM, JW and XW conceived and designed the experiments. WM, JW, and LY performed the experiments and analyzed the data. XW and $Y L$ contributed reagents, materials, and analysis tools. WM and XW wrote the paper. All authors read and approved the final manuscript.

\section{Author details}

${ }^{1}$ State Key Laboratory of Food Science and Technology, Jiangnan University, 1800 Lihu Avenue, Wuxi 214122, China. ${ }^{2}$ International Joint Laboratory on Food Safety, Jiangnan University, Wuxi 214122, China. ${ }^{3}$ Key Laboratory of Industrial Biotechnology, Ministry of Education, School of Biotechnology, Jiangnan University, Wuxi 214122, China.

\section{Acknowledgements}

We are grateful to Prof. Guogiang Chen from Tsinghua University for providing us the pBHR68 vector.

\section{Competing interests}

The authors declare that they have no competing interests.

\section{Availability of data and materials}

All data generated or analyzed during this study are included in the manuscript and additional file.

\section{Funding}

This study was supported by the National First-class Discipline Program of Light Industry Technology and Engineering (LITE2018-10), and the Collaborative Innovation Center of Jiangsu Modern Industrial Fermentation.

\section{Publisher's Note}

Springer Nature remains neutral with regard to jurisdictional claims in published maps and institutional affiliations.

Received: 7 March 2018 Accepted: 8 June 2018

Published online: 15 June 2018

\section{References}

1. Morbach S, Sahm H, Eggeling L. L-Isoleucine production with Corynebacterium glutamicum: further flux increase and limitation of export. Appl Environ Microbiol. 1996;62:4345-51.

2. Eggeling L, Morbach S, Sahm H. The fruits of molecular physiology: engineering the L-isoleucine biosynthesis pathway in Corynebacterium glutamicum. J Biotechnol. 1997:56:167-82.

3. Morbach S, Sahm H, Eggeling L. Use of feedback-resistant threonine dehydratases of Corynebacterium glutamicum to increase carbon flux towards L-isoleucine. Appl Environ Microbiol. 1995;61:4315-20.

4. Morbach S, Kelle R, Winkels S, Sahm H, Eggeling L. Engineering the homoserine dehydrogenase and threonine dehydratase control points to analyse flux towards L-isoleucine in Corynebacterium glutamicum. Appl Microbiol Biotechnol. 1996:45:612-20.

5. Colón GE, Nguyen TT, Jetten MSM, Sinskey AJ, Stephanopoulos G. Production of isoleucine by overexpression of ilvA in a Corynebacterium lactofermentum threonine producer. Appl Microbiol Biotechnol. 1995:43:482-8.

6. Hashiguchi Kl, Kojima H, Sato K, Sano K. Effects of an Escherichia coli ilvA mutant gene encoding feedback-resistant threonine deaminase on L-isoleucine production by Brevibacterium flavum. J Agric Chem Soc Japan. 1997;61:105

7. Guillouet S, Rodal AA, An GH, Gorret N, Lessard PA, Sinskey AJ. Metabolic redirection of carbon flow toward isoleucine by expressing a catabolic threonine dehydratase in a threonine-overproducing Corynebacterium glutamicum. Appl Microbiol Biotechnol. 2001;57:667-73.

8. Xie X, Xu L, Shi J, Xu Q, Chen N. Effect of transport proteins on L-isoleucine production with the L-isoleucine-producing strain Corynebacterium glutamicum YILW. J Ind Microbiol Biotechnol. 2012;39:1549-56.

9. Yin L, Hu X, Xu D, Ning J, Chen J, Wang X. Co-expression of feedbackresistant threonine dehydratase and acetohydroxy acid synthase increase L-isoleucine production in Corynebacterium glutamicum. Metab Eng. 2012;14:542-50.

10. Park JH, Lee SY. Metabolic pathways and fermentative production of L-aspartate family amino acids. Biotechnol J. 2010:5:560-77.

11. Anderson AJ, Dawes EA. Occurrence, metabolism, metabolic role, and industrial uses of bacterial polyhydroxyalkanoates. Microbiol Rev. 1990:54:450-72.

12. Snell KD, Peoples OP. Polyhydroxyalkanoate polymers and their production in transgenic plants. Metab Eng. 2002:4:29-40.

13. Jiang $X-R$, Wang $H$, Shen $R$, Chen G-Q. Engineering the bacterial shapes for enhanced inclusion bodies accumulation. Metab Eng 2015;29:227-37.

14. Yang Q, Wang J, Zhang S, Tang X, Shang G, Peng Q, Wang R, Cai X. The properties of poly(3-hydroxybutyrate-co-3-hydroxyhexanoate) and its applications in tissue engineering. Curr Stem Cell Res Ther. 2014;9:215-22.

15. Choi J, Lee SY. Economic considerations in the production of poly(3hydroxybutyrate-co-3-hydroxyvalerate) by bacterial fermentation. Appl Microbiol Biotechnol. 2000:53:646-9.

16. Jeon JM, Kim HJ, Bhatia SK, Sung C, Seo HM, Kim JH, Park HY, Lee D, Brigham CJ, Yang YH. Application of acetyl-CoA acetyltransferase (AtoAD) in Escherichia coli to increase 3-hydroxyvalerate fraction in poly(3-hydroxybutyrate-co-3-hydroxyvalerate). Bioprocess Biosyst Eng. 2017:40:781-9

17. Shang L, Yim SC, Park HG, Chang HN. Sequential feeding of glucose and valerate in a fed-batch culture of Ralstonia eutropha for production of poly(hydroxybutyrate-co-hydroxyvalerate) with high 3-hydroxyvalerate fraction. Biotechnol Prog. 2004;20:140-4.

18. Bhatia SK, Yi DH, Kim HJ, Jeon JM, Kim YH, Sathiyanarayanan G, Seo HM, Lee $\mathrm{JH}$, Kim JH, Park K, et al. Overexpression of succinyl-CoA synthase for poly (3-hydroxybutyrate-co-3-hydroxyvalerate) production in engineered Escherichia coli BL21(DE3). J Appl Microbiol. 2015;119:724-35.

19. Moorkoth D, Nampoothiri KM. Production and characterization of poly (3-hydroxy butyrate-co-3 hydroxyvalerate)(PHBV) by a novel halotolerant mangrove isolate. Bioresour Technol. 2016;201:253-60.

20. Guo M, Stuckey DC, Murphy RJ. Is it possible to develop biopolymer production systems independent of fossil fuels? Case study in energy profiling of polyhydroxybutyrate-valerate (PHBV). Green Chem. 2013;15:706-17.

21. Raetz CR, Whitfield C. Lipopolysaccharide endotoxins. Annu Rev Biochem. 2002;71:635-700. 
22. Matsumoto K, Kitagawa K, Jo S-J, Song Y, Taguchi S. Production of poly (3-hydroxybutyrate-co-3-hydroxyvalerate) in recombinant Corynebacterium glutamicum using propionate as a precursor. J Biotechnol. 2011;152:144-6.

23. Liu Q, Ouyang S-P, Kim J, Chen G-Q. The impact of PHB accumulation on L-glutamate production by recombinant Corynebacterium glutamicum. J Biotechnol. 2007;132:273-9.

24. Gu P, Kang J, Yang F, Wang Q, Liang Q, Qi Q. The improved L-tryptophan production in recombinant Escherichia coli by expressing the polyhydroxybutyrate synthesis pathway. Appl Microbiol Biotechnol. 2013;97:4121-7.

25. Xu M, Qin J, Rao Z, You H, Zhang X, Yang T, Wang X, Xu Z. Effect of polyhydroxybutyrate $(\mathrm{PHB})$ storage on L-arginine production in recombinan Corynebacterium crenatum using coenzyme regulation. Microb Cell Fact. 2016;15:15.

26. Kang Z, Gao C, Wang Q, Liu H, Qi Q. A novel strategy for succinate and polyhydroxybutyrate co-production in Escherichia coli. Bioresour Technol. 2010;101:7675-8.

27. Xu D, Tan Y, Huan X, Hu X, Wang X. Construction of a novel shuttle vector for use in Brevibacterium flavum, an industrial amino acid producer. J Microbiol Methods. 2010;80:86-92.

28. Wang $Y$, Wu H, Jiang $X$, Chen G-Q. Engineering Escherichia coli for enhanced production of poly (3-hydroxybutyrate-co-4-hydroxybutyrate) in larger cellular space. Metab Eng. 2014;25:183-93.

29. Armando J, Boghigian B, Pfeifer B. LC-MS/MS quantification of shortchain acyl-CoA's in Escherichia coli demonstrates versatile propionyl-CoA synthetase substrate specificity. Lett Appl Microbiol. 2012;54:140-8.

30. Gao L, Chiou W, Tang H, Cheng X, Camp HS, Burns DJ. Simultaneous quantification of malonyl-CoA and several other short-chain acyl-CoAs in animal tissues by ion-pairing reversed-phase HPLC/MS. J Chromatogr B. 2007:853:303-13.

31. Bennett BD, Kimball EH, Gao M, Osterhout R, Van Dien SJ, Rabinowitz JD. Absolute metabolite concentrations and implied enzyme active site occupancy in Escherichia coli. Nat Chem Biol. 2009;5:593-9.

32. Becker J, Wittmann C. Bio-based production of chemicals, materials and fuels-Corynebacterium glutamicum as versatile cell factory. Curr Opin Biotechnol. 2012;23:631-40.

33. Hyatt D, Chen G-L, LoCascio PF, Land ML, Larimer FW, Hauser LJ. Prodigal: prokaryotic gene recognition and translation initiation site identification. BMC Bioinform. 2010;11:119.

34. Berlin K, Koren S, Chin CS, Drake JP, Landolin JM, Phillippy AM. Assembling large genomes with single-molecule sequencing and locality-sensitive hashing. Nat Biotechnol. 2015;33:623-30.

35. Lowe TM, Chan PP. tRNAscan-SE On-line: integrating search and context for analysis of transfer RNA genes. Nucleic Acids Res. 2016;44:W54-7.

36. Nawrocki EP, Burge SW, Bateman A, Daub J, Eberhardt RY, Eddy SR, Floden EW, Gardner PP, Jones TA, Tate J, Finn RD. Rfam 12.0: updates to the RNA families database. Nucleic Acids Res. 2015;43:D130-7.

37. Yang J, Yang S. Comparative analysis of Corynebacterium glutamicum genomes: a new perspective for the industrial production of amino acids. BMC Genomics. 2017:18:940.

38. Yin L, Hu X, Wang X. Proteomic analysis of L-isoleucine production by Corynebacterium glutamicum. J Pure Appl Microbiol. 2014;8:899-908.

39. Lange C, Mustafi N, Frunzke J, Kennerknecht N, Wessel M, Bott M, Wendisch VF. Lrp of Corynebacterium glutamicum controls expression of the brnFE operon encoding the export system for L-methionine and branched-chain amino acids. J Biotechnol. 2012;158:231-41.

40. Yin L, Shi F, Hu X, Chen C, Wang X. Increasing L-isoleucine production in Corynebacterium glutamicum by overexpressing global regulator Lrp and two-component export system BrnFE. J Appl Microbiol. 2013;114:1369-77.

41. Krömer J, Wittmann C, Schröder H, Heinzle E. Metabolic pathway analysis for rational design of L-methionine production by Escherichia coli and Corynebacterium glutamicum. Metab Eng. 2006:8:353-69.

42. Vogt M, Haas S, Klaffl S, Polen T, Eggeling L, Van OJ, Bott M. Pushing product formation to its limit: metabolic engineering of Corynebacterium glutamicum for L-leucine overproduction. Metab Eng. 2014;22:40-52.

43. Becker J, Klopprogge C, Schroder H, Wittmann C. Metabolic engineering of the tricarboxylic acid cycle for improved lysine production by Corynebacterium glutamicum. Appl Environ Microbiol. 2009;75:7866-9.
44. Ruiz JA, López NI, Méndez BS. rpoS gene expression in carbon-starved cultures of the polyhydroxyalkanoate-accumulating species Pseudomonas oleovorans. Curr Microbiol. 2004:48:396-400.

45. Zhao YH, Li HM, Qin LF, Wang HH, Chen G-Q. Disruption of the polyhydroxyalkanoate synthase gene in Aeromonas hydrophila reduces its survival ability under stress conditions. FEMS Microbiol Lett. 2007;276:34-41.

46. Ma W, Wang J, Li Y, Hu X, Shi F, Wang X. Enhancing pentose phosphate pathway in Corynebacterium glutamicum to improve L-isoleucine production. Biotechnol Appl Biochem. 2016:63:877-85.

47. Hori K, Kobayashi A, Ikeda H, Unno H. Rhodococcus aetherivorans IAR1, a new bacterial strain synthesizing poly(3-hydroxybutyrate-co-3-hydroxyvalerate) from toluene. J Biosci Bioeng. 2009;107:145-50.

48. Chen CW, Don T-M, Yen H-F. Enzymatic extruded starch as a carbon source for the production of poly(3-hydroxybutyrate-co-3-hydroxyvalerate) by Haloferax mediterranei. Process Biochem. 2006;41:2289-96.

49. Han J, Li M, Hou J, Wu L, Zhou J, Xiang H. Comparison of four phaC genes from Haloferax mediterranei and their function in different PHBV copolymer biosyntheses in Haloarcula hispanica. Saline Syst. 2010;6:9.

50. Kulkarni SO, Kanekar PP, Nilegaonkar SS, Sarnaik SS, Jog JP. Production and characterization of a biodegradable poly (hydroxybutyrate-cohydroxyvalerate) (PHB-co-PHV) copolymer by moderately haloalkalitolerant Halomonas campisalis MCM B-1027 isolated from Lonar Lake, India. Bioresour Technol. 2010;101:9765-71.

51. Wang Q, Liu X, Qi Q. Biosynthesis of poly (3-hydroxybutyrate-co-3-hydroxyvalerate) from glucose with elevated 3-hydroxyvalerate fraction via combined citramalate and threonine pathway in Escherichia coli. Appl Microbiol Biotechnol. 2014:98:3923-31.

52. Jo S-J, Maeda M, Ooi T, Taguchi S. Production system for biodegradable polyester polyhydroxybutyrate by Corynebacterium glutamicum. J Biosci Bioeng. 2006;102:233-6.

53. Bisswanger $\mathrm{H}$. Substrate specificity of the pyruvate dehydrogenase complex from Escherichia coli. J Biol Chem. 1981;256:815-22.

54. Aldor IS, Kim SW, Prather KL, Keasling JD. Metabolic engineering of a novel propionate-independent pathway for the production of poly(3hydroxybutyrate-co-3-hydroxyvalerate) in recombinant Salmonella enterica serovar typhimurium. Appl Environ Microbiol. 2002;68:3848-54.

55. Jaremko M, Yu J. The initial metabolic conversion of levulinic acid in Cupriavidus necator. J Biotechnol. 2011:155:293-8.

56. Berezina N, Yada B. Improvement of the poly(3-hydroxybutyrate-co-3-hydroxyvalerate) (PHBV) production by dual feeding with levulinic acid and sodium propionate in Cupriavidus necator. N Biotechnol. 2016;33:231-6.

57. Yin L, Zhao J, Chen C, Hu X, Wang X. Enhancing the carbon flux and NADPH supply to increase L-isoleucine production in Corynebacterium glutamicum. Biotechnol Bioprocess Eng BBE. 2014;19:132.

58. Vogt M, Krumbach K, Bang WG, van Ooyen J, Noack S, Klein B, Bott M, Eggeling $L$. The contest for precursors: channelling L-isoleucine synthesis in Corynebacterium glutamicum without byproduct formation. Appl Microbiol Biotechnol. 2015;99:791-800.

59. Lee EY, Kang SH, Choi CY. Biosynthesis of poly (3-hydroxybutyrate-co3-hydroxyvalerate) by newly isolated Agrobacterium sp. SH-1 and GW-014 from structurally unrelated single carbon substrates. J Ferment Bioeng. 1995;79:328-34.

60. Choi GG, Kim MW, Kim JY, Rhee YH. Production of poly(3-hydroxybutyrate-co-3-hydroxyvalerate) with high molar fractions of 3-hydroxyvalerate by a threonine-overproducing mutant of Alcaligenes sp. SH-69. Biotechnol Lett. 2003;25:665-70.

61. Lu Q, Han J, Zhou L, Zhou J, Xiang H. Genetic and biochemical characterization of the poly(3-hydroxybutyrate-co-3-hydroxyvalerate) synthase in Haloferax mediterranei. J Bacteriol. 2008;190:4173-80.

62. Zhang YZ, Liu GM, Weng WQ, Ding JY, Liu SJ. Engineering of Ralstonia eutropha for the production of poly(3-hydroxybutyrate-co-3-hydroxyvalerate) from glucose. J Biotechnol. 2015;195:82-8.

63. Spiekermann P, Rehm BH, Kalscheuer R, Baumeister D, Steinbuchel A. A sensitive, viable-colony staining method using Nile red for direct screening of bacteria that accumulate polyhydroxyalkanoic acids and other lipid storage compounds. Arch Microbiol. 1999;171:73-80. 